\title{
Reproductive Factors of Dengue and Chlamydia
}

\author{
Kiran Raj Awasthi ${ }^{1}$ and Mamata Sherpa Awasthi ${ }^{2 *}$ \\ ${ }^{1}$ Program Manager-Malaria program, Save the Children International, Nepal \\ ${ }^{2}$ Department of Nursing, Janamaitri Foundation Institute of Health Sciences, Nepal
}

Submission: February 18, 2019; Published: May 03, 2019

*Corresponding author: Mamata Sherpa Awasthi, Assistant Professor, Department of Nursing, Janamaitri Foundation Institute of Health Sciences, Hattiban, Lalitpur, Nepal

\begin{abstract}
Introduction: Dengue is a common mosquito borne infectious disease often occurring in tropical and subtropical climates caused by single stranded positive RNA viruses (DENV1-4) of the genus Flavivarus and family Flaviviridae while Chlamydia is a STD commonly prevalent in industrialized countries and is caused by Chlamydia trachomatis, a gram negative bacteria.

Reproductive Factor $\mathbf{R}_{0}$ : The $R_{0}$ of any infection is the average number of cases a single infected case can generate during its infectious period in an infection free population and is influenced by several factors including number of contacts with an infected population, infective duration of patients, and infectiousness of the causative organism. The $\mathrm{R}_{0}$ for dengue varies with temperature and increases during outbreaks. The $\mathrm{R}_{0}$ for dengue in urban Australian settings will most likely be $<1$ although it has a tendency to be $>1$ during outbreaks. Dengue infections for people in urban Australian setting is mostly attributed to travels to dengue endemic areas mainly South East Asia (Thailand, Indonesia, Philippines) as preferred destinations which are major sources of dengue outbreaks. The $\mathrm{R}_{0}$ for Chlamydia is difficult to calculate due to longer duration of infectivity, changing rates of partners and constant change in population over time.
\end{abstract}

Conclusion: Urban dwelling with a higher population coupled with risk factors including travelling abroad to risk countries in South East Asia where prevalence of Dengue and Chlymadia is high could lead to $\mathrm{R}_{0}$ being more than 1 if it is not traced early and treated. Its prevention has been adversely affected by various social, environmental and behavioral factors.

Keywords: Reproductive factor; Migration; Risk behaviors; Dengue; Chlamydia

Abbreviations: STDs: Sexually Transmitted Diseases; DHF: Dengue Hemorrhagic Fever; DSS: Dengue Shock Syndrome; EIP: Extrinsic Incubation Period; IIP: Intrinsic Incubation Period; PID: Pelvic Inflammatory Disease; SES: SocioEconomic Status

\section{Introduction}

Over fourteen hundred different infectious agents cause diseases in humans of which around three hundred pathogens are clinically important [1]. Although developing countries are epitomized as reservoirs for infectious diseases, developed countries also bear the disease burden. Australia reports 67 different types of prevalent infectious diseases of which $40.1 \%$ are sexually transmitted diseases (STDs), 34.4\% vaccine preventable diseases and $13.8 \%$ gastrointestinal diseases [2]. Common infectious diseases occurring in developing countries such as STDs, influenza, measles, hepatitis A B and C, cholera, botulism, dengue, malaria also exist in Australia [2]. This paper elaborates on dengue and chlamydia, and the factors that would affect the transmission and natural history of the two in three different settings.

\section{Dengue}

Dengue is a common mosquito borne infectious disease often occurring in tropical and subtropical climates. The primary vector for transmitting the disease is the female Aedes aegypti mosquito which transmits one or multiple forms of the single stranded positive RNA viruses (DENV1-4) of the genus Flavivarus and family Flaviviridae [3]. An estimated 50\% of world's population is at risk of dengue while 50 to 100 million new infections occur annually [4]. Of these around $70 \%$ of dengue cases are centered in South East Asian and Western Pacific countries [5]. India alone reported 33 million infections while Brazil and Mexico reported over 5 million infections annually [4]. Despite a decline from 1406 to 1201 cases between 2009 and 2010 in Australia, the risk of the dengue outbreak still remains [6]. Between 1991 and 1999 small and large locally acquired outbreaks of dengue in Queensland alone accounted for $77 \%$ of the total 2139 cases reported in the region [7].

Generally, children, women, people having high body mass index are vulnerable groups for severe dengue [3]. Annually 500,000 people with either dengue hemorrhagic fever (DHF) or dengue shock syndrome (DSS) are hospitalized of which $2.5 \%$ die [8]. Although Australia has no dengue related deaths, countries such as India and Indonesia report a case fatality between 3 to $5 \%$ 


\section{Global Journal of Reproductive Medicine}

[1]. Dengue is transmitted by Aedes mosquitoes which bites and feeds multiple times during the day [3]. The transmission cycle starts after a female mosquito bites an infected individual during the viraemic period [9]. The extrinsic incubation period (EIP) for dengue (the period virus takes to make a blood fed mosquito to be infectious) is between 8 to 10 days while the intrinsic incubation period (IIP), time for symptoms to appear in humans, range from 4 to 12 days [10]. The EIP is influenced by factors such as temperature, rainfall and humidity [9]. Dengue infections can further evolve into more serious DHF or hemorrhagic dengue which can be fatal [3].

\section{Chlamydia}

Chlamydia is a STD commonly prevalent in industrialized countries and is caused by Chlamydia trachomatis, a gram negative bacteria of serotype $\mathrm{D}-\mathrm{K}$ [11]. It can cause prostatitis and epididymitis in males while cervicitis, pelvic inflammatory disease (PID), ectopic pregnancy are observed in females [12]. Most infections are asymptomatic and go unnoticed resulting in long term complications [13]. Although case fatality of chlamydia infections is negligible, complications such as PID can cause infertility especially among females. Ever year 24,000 women become infertile in the United States due to untreated chlamydial infections [14]. An estimated 105.7 million new infections occur globally with $5 \%$ of these occurring in European countries [15]. A prevalence ranging from $5.7 \%$ to $17 \%$ was observed among screened pregnant women in Thailand and India respectively [15]. In 2012, 1.4 million cases of Chlamydia infections were reported in the United States [14]. It is the most common type of STD affecting Australian population with over 80,000 cases $(357.2$ per 100,000 population) in 2011 with a higher prevalence among the indigenous population $[2,16]$. Indigenous Australians tested at health centers and antenatal clinics in 2009 reported prevalence rates of $14.8 \%$ and $12.3 \%$ respectively [11].

Chlamydia risk groups include sexually active young males and females who practice unprotected sex, have multiple sex partners, heterosexuals and men having sex with men [14]. The transmission is direct through exchange of body fluids either from unprotected sex or vertical from an untreated mother to her child during birth [17]. Chlamydia bacteria during its life cycle continuously interchange between a non replicating infectious elementary state and a replicating non infectious reticulate state. Under suitable environment inside the cell of a host the bacteria converts into a reticulate form which multiplies every 2-3 hours and the EIP for this state of the bacteria is between 7-21 days [18]. Although the IIP for Chlamydia is not well defined, symptoms can still develop as late as several weeks after exposure [14].

\section{Basic reproductive rate (R0)}

The $R_{0}$ of any infection is the average number of cases a single infected case can generate during its infectious period in an infection free population where $a R_{0}>1$ indicates a higher possibility of an outbreak while $\mathrm{R}_{0}<1$ indicates the infection could cease over a period of time [19]. $R_{0}$ is influenced by several factors including number of contacts with an infected population, infective duration of patients, and infectiousness of the causative organism [9].

\section{$\mathbf{R}_{0}$ for Dengue}

The $\mathrm{R}_{0}$ for dengue varies with temperature and increases during outbreaks. Multiple studies have indicated it to range between 1.33 to 11.6 [20]. The $R_{0}$ during 1990 outbreak of dengue in Sao Paolo was 2.03 while a similar episode in Mexico reported a maximum $R_{0}$ of 2.41[21]. Dengue has been described by epidemiologists as urban malaria [3]. The $R_{0}$ for dengue in urban Australian settings will most likely be $<1$ although it has a tendency to be $>1$ during outbreaks. Dengue infections for people in urban Australian setting is mostly attributed to travels to dengue endemic areas mainly South East Asia (Thailand, Indonesia, Philippines) as preferred destinations which are major sources of dengue outbreaks [7]. A total of 4965 out of 7693 dengue cases since 2000 can be related to overseas travel with Bali being responsible for $80 \%$ of these cases [7]. Once identified, the infected are treated early thereby decreasing possibility of further infections. Furthermore, some areas of Australia especially Northeast parts of Queensland indicate that Aedes segypti is well established locally [7]. The presence of the vectors could increase the $\mathrm{R}_{0}>1$ in these areas [22].

Major features of urban slums in developing countries and remote Australian Aboriginal population are large family sizes, overcrowding, poor housing facilities, lack of sanitation and proper waste management, use of storage containers for water due to lack of pipe lines all of which can provide suitable environment for the vector to breed and become active thereby increase risks of recurrent or chronic infections [23]. In both settings, people stay outdoors in groups and socialize more, increasing the number of contacts and susceptibility to mosquito bites leading to increase in $R_{0}$ [23]. However due to the lack of Aedes mosquito in Australia except for some parts of Queensland the $R_{0}<1$ in Aboriginal settings whereas it will be $>1$ for urban slums in developing countries. Some control measures to decrease the $R_{0}$ are to decrease the contacts which could mean staying indoors in highrisk areas and indoor/outdoor residual spraying of pesticides to control the breeding areas of Aedes. For urban areas of Australia, screenings of travelers can be done at airports to identify and quarantine cases early. Furthermore, health awareness and promotion activities can be conducted in urban slums and remote areas regarding dengue.

\section{$\mathbf{R}_{\mathbf{0}}$ for Chlamydia}

The $\mathrm{R}_{0}$ for Chlamydia is difficult to calculate due to longer duration of infectivity, changing rates of partners and constant change in population over time [18]. A 10 month study done in Canada revealed an average R0 for participants with one sex partner to be between 0.7 and $0.97(\mathrm{R} 0<1)$ while for repeated sex with multiple partners to be between 1 and 1.09 (R0>1) [24]. The R0 could be slightly $>1$ in all the three settings (Australian urban, remote Aboriginal and urban slums of developing 


\section{Global Journal of Reproductive Medicine}

countries), however, the factors affecting it could vary. Urban areas of Australia have seen population growth due to inter country migration (could include infected population from other countries) or through Aboriginal population from remote areas of the country [11]. Similar episodes are seen in urban areas of developing countries. This would increase the number of contacts leading to increased $\mathrm{R}_{0}$.

Often lone travelers from urban Australia visit countries like Thailand and Indonesia and indulge in unprotected sex with sex workers or travel partners thereby increasing the risk of Chlamydia transmission [25]. Urban cites in Australia often host big events such as concerts, festivals drawing large crowds while the younger adults are seen clubbing and going to bars frequently [26]. This behavior could increase episodes of unprotected sex either under intoxication or for fun thereby increasing the risk of transmission. A study done in a mega musical event in Melbourne in 2005 indicated $44 \%$ of the participants having unprotected sex after such events while $47 \%$ reported more than two sexual partners in the previous year [27].

People in rural Aboriginal communities and urban slums of developing countries who abuse alcohol also practice risky sex behaviors causing increased transmission [16]. More than $70 \%$ of single men under 30years living in the poorer suburbs of Goa consumed alcohol and practices unprotected sex at least once [28]. Furthermore, reluctance of males to buy and use condoms during sex is another reason for increased transmission in the latter two settings [11]. The incubation and asymptomatic period of the chlamydia is long. This could encourage infection spread especially among young people who practice sex with multiple partners.

Some measures for controlling chlamydia are free distribution or establishing vending stalls of condoms in areas of mass gathering, increasing health literacy and awareness on STD targeting young age groups and travelers, making condoms and testing sites available and affordable in rural Aboriginal settings and urban slums in developing countries.

\section{Factors affecting the natural history of the diseases}

Several factors affect the natural history of dengue and chlamydial infections. Although urban cities in Australia are well equipped with health facilities to control for dengue epidemics, however, it could be a challenge for remote Aboriginal and urban slums of developing countries. Lack of access to health care facilities, or trained health personnel in the later settings could lead to late diagnosis and poor treatment of diseases such as chlamydia and dengue causing morbidity, increased infections rates, severe secondary infections and deaths [3]. Socioeconomic status (SES) is also an important factor as ability to access and afford care, medications and nutritious food required to promote recovery. This would invariably affect disease progression in both these infections.

Individual immunity also affects disease progression. In higher SES groups like most Australian urban societies, better quality of life generally leads to higher immunity which means the body can better fight infections and limit the onset of diseases or complications. However, in lower SES such as Aboriginal population and people in urban slums of developing countries with poorer quality of life, immunity can be potentially compromised by several other lifestyle factors, thereby making it easier for infections to progress to disease and if not treated, complications.

Health literacy is associated with health seeking behavior which is further complicated by social factors such as socioeconomic status and culture (socializing, using condoms) for both dengue and chlamydial infections [29]. Lack of awareness about STDs such as Chlamydia among the younger population in all three settings is common which invariably increases the infections rates [27]. Lifestyle behaviors could play an important role in disease progression. Risk taking behaviors and neglect are common among younger age groups in urban cities of Australia and Aboriginal communities leading to increased chlamydial infections. Unemployment, substance abuse could add further impetus to the risk behaviors especially among Aboriginal communities [23]. In developing countries such as India, fear and shame of screening and treatment procedures for chlamydial infections increases possible further complication and spread [30].

\section{Conclusion}

Dengue and chlamydia are common infectious diseases affecting population not only in Australia but all over the world. However, social, environmental and behavioral factors associated with the vector host have affected the prevention and control of these two public health problems. However, efforts to detect them early, improve health literacy and change the environment could be some major steps towards their control.

\section{References}

1. Hay SI, Battle KE, Pigott DM, Smith DL, Moyes CL, et al. (2013) Global mapping of infectious disease. Philos Trans R Soc Lond B Biol Sci 368(1614): 20120250.

2. NNDSS AR (2011) Australia's notifiable disease status, 2011: annual report of the National Notifiable Diseases Surveillance System. Communicable diseases intelligence quarterly report. 37(4): E313.

3. Simmons CP, Farrar JJ, van Vinh Chau N, Wills B (2012) Dengue. N Engl J Med 366(15): 1423-1432.

4. Bhatt S, Gething PW, Brady OJ, Messina JP, Farlow AW, Moyes CL, Drake JM, Brownstein JS, Hoen AG, Sankoh O, Myers MF. The global distribution and burden of dengue. Nature. 2013 Apr;496(7446):504.

5. Karyanti MR, Uiterwaal CS, Kusriastuti R, Hadinegoro SR, Rovers MM, et al. (2014) The changing incidence of Dengue Haemorrhagic Fever in Indonesia: a 45-year registry-based analysis. BMC Infect Dis 14(1): 412.

6. (2012) Australian Bureau of Statistics. Year Book Australia. Canberra.

7. Knope K, Giele C (2012) Increasing notifications of dengue in Australia related to overseas travel, 1991 to 2012 . Communicable diseases intelligence quarterly report 37(1): E55.

8. Ratnam I, Black J, Leder K, Biggs BA, Matchett E, et al. (2013) Incidence and seroprevalence of dengue virus infections in Australian travellers to Asia. Eur J Clin Microbiol Infect Dis 31(6): 1203-1210. 
9. Yang HM, Macoris ML, Galvani KC, Andrighetti MT, Wanderley DM (2009) Assessing the effects of temperature on dengue transmission. Epidemiol Infect 137(8): 1179-1187.

10. Chan M, Johansson MA (2012) The incubation periods of dengue viruses. PloS one 7(11): e50972.

11. Ward J, Goller J, Ali H, Bowring A, Couzos S, et al. (2014) Chlamydia among Australian Aboriginal and/or Torres Strait Islander people attending sexual health services, general practices and Aboriginal community controlled health services. BMC Health Serv Res 14(1): 285.

12. Lewis D, Newton DC, Guy RJ, Ali H, Chen MY, et al. (2012) The prevalence of Chlamydia trachomatis infection in Australia: a systematic review and meta-analysis. BMC Infect Dis 12(1): 113.

13. Goulet V, de Barbeyrac B, Raherison S, Prudhomme M, Semaille C, et al. (2010) Prevalence of Chlamydia trachomatis: results from the first national population-based survey in France. Sex Transm Infect 86(4): 263-270.

14. (2012) Centers for Disease Control and Prevention. Sexually Transmitted Disease Surveillance, 2012. Atlanta: Centers for Disease Control and Prevention.

15. (2008) World Health Organization. Global incidence and prevalence of selected curable sexually transmitted infections. Geneva: World Health Organization

16. O’Connor CC, Ali H, Guy R, Templeton D, Fairley C, et al. (2014) High chlamydia positivity rates in Indigenous people attending Australian sexual health services. Med J Aust 200(10): 595-598.

17. Van Bergen J, Götz H, Richardus J, Hoebe C, Broer J, et al. (2005) Prevalence of urogenital Chlamydia trachomatis increases significantly with level of urbanisation and suggests targeted screening approaches: results from the first national population based study in the Netherlands. Sex Transm Infect 81(1): 17-23.

18. Navarro C, Jolly A, Nair R, Chen Y (2002) Risk factors for genital chlamydial infection. Can J Infect Dis 13(3): 195-207.

19. Wilson D (2004) Mathematical modelling of Chlamydia. ANZIAM Journal 45: C201-C14.

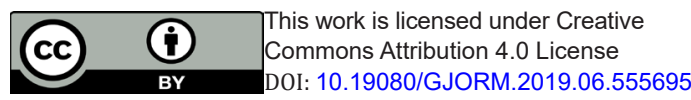

20. Hanley KA, Weaver SC (2010) Frontiers in Dengue Virus Research: Horizon Scientific Press.

21. Marques C, Forattini O, Massad E (1994) The basic reproduction number for dengue fever in Sao Paulo state, Brazil: 1990-1991 epidemic. Trans R Soc Trop Med Hyg 88(1): 58-59.

22. Russell RC, Currie BJ, Lindsay MD, Mackenzie JS, Ritchie SA, Whelan PI (2009) Dengue and climate change in Australia: predictions for the future should incorporate knowledge from the past. Med J Aust 190(5): 265-268.

23. Gracey M, King M (2009) Indigenous health part 1: determinants and disease patterns. Lancet 374(9683): 65-75.

24. Jolly A, Wylie J (2002) Gonorrhoea and chlamydia core groups and sexual networks in Manitoba. Sex Transm Infect 78(suppl 1): i145-i51.

25. Richens J (2006) Sexually transmitted infections and HIV among travellers: a review. Travel Med Infect Dis 4(3): 184-95.

26. Dumas TM, Wells S, Flynn A, Lange JE, Graham K (2014) The influence of status on group drinking by young adults: a survey of natural drinking groups on their way to and from bars. Alcohol Clin Exp Res 38(4): 1100-1107.

27. Lim MS, Hellard ME, Aitken CK, Hocking JS (2007) Sexual-risk behaviour, self-perceived risk and knowledge of sexually transmissible infections among young Australians attending a music festival. Sex health $4(1)$ : 51-6.

28. Pillai A, Nayak MB, Greenfield TK, Bond JC, Hasin DS, et al. (2014) Adolescent drinking onset and its adult consequences among men: a population based study from India. J Epidemiol Community Health 68(10): 922-927.

29. Osborn CY, Paasche-Orlow MK, Bailey SC, Wolf MS (2011) The mechanisms linking health literacy to behavior and health status. Am J Health Behav 35(1): 118-128.

30. Ghosh P, Arah O, Talukdar A, Sur D, Babu G, et al. (2011) Factors associated with HIV infection among Indian women. Int J STD AIDS 22(3): 140-145.

Your next submission with Juniper Publishers
will reach you the below assets
- Quality Editorial service
- Swift Peer Review
- Reprints availability
- E-prints Service
- Manuscript Podcast for convenient understanding
- Global attainment for your research
- Manuscript accessibility in different formats
( Pdf, E-pub, Full Text, Audio)
- Unceasing customer service
Track the below URL for one-step submission
https://juniperpublishers.com/online-submission.php

